\title{
Evaluation of physical and cardiorespiratory fitness in 7-year-old prematurely born children - preliminary study
}

\author{
Anna Kosiecz ${ }^{1, A-F} \oplus$, Magdalena Chrościńska-Krawczyk ${ }^{1, A-F}{ }^{\oplus}$, Jolanta Taczała ${ }^{2, A-F} \oplus$, \\ Magdalena Zawadka ${ }^{3, C-F \oplus}$ \\ ${ }^{1}$ Third Department of Paediatrics, Children's Neurology Clinic, Medical University, Lublin, Poland \\ ${ }^{2}$ Department of Rehabilitation and Physioterapy, Medical University, Lublin, Poland \\ ${ }^{3}$ Department of Sports Medicine, Faculty of Health Science, Medical University, Lublin, Poland \\ A - Research concept and design, B - Collection and/or assembly of data, C - Data analysis and interpretation, \\ $D$ - Writing the article, $E$ - Critical revision of the article, $F$ - Final approval of article
}

Kosiecz A, Chrościńska-Krawczyk M, Taczała J, Zawadka M. Evaluation of physical and cardiorespiratory fitness in 7-year-old prematurely born children - preliminary study. Ann Agric Environ Med. 2021; 28(3): 502-508. doi: 10.26444/aaem/127220

\begin{abstract}
Introduction. Premature birth is connected with the risk of incidence of numerous health complications, the consequences of which are observed in the long-term. Decreased physical and cardiorespiratory fitness can also be associated with preterm birth.

Objective. The aim of the study is evaluation of the development level of physical and cardiorespiratory fitness in 7-yearold prematurely born children.

Materials and method. The following 7-year-old children were qualified for participation in the research: $30 \mathrm{children} \mathrm{born}$ on time and 30 children born prematurely. Physical fitness was evaluated with the International Physical Fitness Test (IPFT), whereas cardiorespiratory fitness was assessed on the basis of the Kasch Pulse Recovery Test.

Results. The results obtained demonstrate a lower level of physical and cardiorespiratory fitness in the studied group. Statistically significant differences are noticeable with respect to all IPFT components, except for long jump. The studied group display statistically significant higher values of pulse rate after exercise than the control group. On the other hand, there is no statistically significant correlation between a child's gestational age week of birth and the parameters evaluated. Conclusions. 7-year-old prematurely born children present lower physical and cardiorespiratory fitness than children born on time. The research results show a need for long-term monitoring of prematurely born children's development, as well as overall body efficiency. Further studies and observation of a higher number of patients are planned in order to confirm the findings.
\end{abstract}

\section{Key words}

preterm birth, cardiorespiratory fitness, public health, physical fitness

\section{INTRODUCTION}

Preterm birth is associated with the risk of health problems in the prenatal period, higher mortality in infancy, developmental abnormalities and more frequent incidence of health complications in adult life [1,2]. Every year, ca. 14.9 million babies are born before the $37^{\text {th }}$ week of gestational age, which accounts for $11 \%$ of all births on a global scale [3]. This is a substantial group of people at risk of health problems. Children with a diagnosis of disability or serious complications are covered by comprehensive medical care. On the other hand, prematurely born children with no diagnosis of health problems function in society in the same way as children who do not need any additional observation or support. Nevertheless, developmental differences between prematurely born children and those born on time are observed throughout their whole lifetime. Long-term observation of progress reveals deficits related both to the overall body function and cognitive development [4]. Furthermore, at a later age, those born prematurely run

Address for correspondence: Anna Kosiecz, Third Department of Paediatrics, Children's Neurology Clinic, Medical University, Lublin, Poland

E-mail: kosiecz.anna@gmail.com

Received: 13.07.2020; accepted: 03.09.2020; first published: 09.09.2020 an increased risk of falling ill with such diseases as: diabetes, obesity, asthma and mental disorders. Attention is also paid to the body efficiency in the context of the cardiorespiratory function and physical fitness. The long-term effects of premature birth include decreased parameters of the aformentioned functions, which can predispose prematurely born people to cardiological, metabolic and other chronic diseases $[2,5]$.

The outcomes of long-term evaluation of prematurely born children's development also depend on additional health problems. Decreased lung efficiency, oxygen therapy in the newborn period, mechanical ventilation, chronic lung disease and frequent respiratory infections are regarded as significant factors which can impair lung function and later reduce effort tolerance $[6,7]$.

Early childhood is an important period for development of motor functions and enhancement of body fitness. This is the time of optimal motor advancement and dynamic developmental changes. A 7-year-old child should master almost a half of the movements typical of an adult. Owing to the development of myelination and inervation processes, a child's movements become harmonious and precise. Motor ability should reach a high level at that time [8]. In view of the risk of a decreased level of physical and cardiorespiratory 
fitness, the authors undertook the task of evaluating the above-mentioned parameters in 7-year-old prematurely born children. Due to considerable sensitivity of this developmental stage in terms of enhancement of motor skills, such evaluation and preventive actions introduced at this stage, if needed, seem justified

\section{OBJECTIVE}

The aim of the study is evaluation of the physical and cardiorespiratory fitness in 7-year-old prematurely born children, and the identification of correlations between gestational age week of a child's birth and level of physical and cardiorespiratory fitness.

\section{MATERIALS AND MEHOD}

The research covered 60 children aged 7 years (36 girls and 24 boys). The studied group of prematurely born children comprised 22 girls and 8 boys, whereas the control group of children born on time consisted of 14 girls and 16 boys (Tab. 1). Participation in the study was voluntary. An announcement about the study of premature babies was published in the local press, educational institutions and social media. Parents volunteered to participate. The control group study was conducted in the first grade of primary school. The criterion for inclusion into the control group was age: 7 years old, regardless of gender. The criteria for inclusion into the studied group were: age (7 years old) and preterm birth $\left(<37^{\text {th }}\right.$ week of gestational age (g.a.)). The preterm children were born between the $24^{\text {th }}-32^{\text {nd }}$ week of g.a. (29.6, on average) (Tab. 2). The exclusion criteria for both groups were: disability, physical effort contraindicated by a doctor, comorbidities affecting the body function, i.e. asthma, cardiorespiratory failure, cardiovascular diseases, and lack of parental consent for participation in the study. All participants of the research lived in the Lublin Province in Poland.

Table 1. Comparison of the groups in terms of number of participants

\begin{tabular}{lccc}
\hline Group & Gender & Number [n] & Percentage [\%] \\
\hline Studied & Girls & 22 & 73.33 \\
\hline Total & Boys & 8 & 26.67 \\
\hline Control & & 30 & 100 \\
\hline & Girls & 14 & 46.67 \\
\hline Total & Boys & 16 & 53.33 \\
\hline
\end{tabular}

Table 2. Description of the studied group, number of participants in relation to gestational age week of birth

\begin{tabular}{lccc}
\hline Birth time & $\begin{array}{c}32^{\text {th }}-36^{\text {th }} \text { week } \\
\text { of g.a. }\end{array}$ & $\begin{array}{c}28^{\text {th }}-31^{\text {st }} \text { week } \\
\text { of g.a. }\end{array}$ & $\begin{array}{c}24^{\text {th }}-27^{\text {th }} \text { week } \\
\text { of g.a. }\end{array}$ \\
\hline $\begin{array}{l}\text { No. of participants in } \\
\text { the studied group }\end{array}$ & 3 & 21 & 6 \\
\hline
\end{tabular}

The International Physical Fitness Test (IPFT) was used to evaluate physical fitness. This is a standardized battery of tests, created as a simple, practical, reliable and objective tool for the measurement of physical fitness. It enables analysis of physical fitness measurement and of changes taking place over time. The participants performed 8 fitness tests, the results of which enable evaluation of the development level in such areas of physical fitness as: speed, jumping ability, stamina, muscle strength, agility and suppleness. The IPTF comprises the following fitness tests: 50-meter sprint, standing long jump, grip strength, flexed-arm bar hang, $4 \times 10$-meter shuttle run with carrying blocks, standing trunk flexion, 30-second sit-ups, 600-meter run (Tab. 3) [9].

Table 3. IPFT components and measurement methods.

\begin{tabular}{lc}
\hline $\begin{array}{l}\text { International Physical Fitness Test } \\
\text { component }\end{array}$ & Measurement method / unit \\
\hline Long jump & Tape measure / cm \\
\hline Grip strength & Hand dynamometer / kg \\
\hline Bar hang & Stopwatch / sec \\
\hline $4 \times 10$-meter shuttle run & Stopwatch / sec \\
\hline 50 -meter sprint & Stopwatch / sec \\
\hline Standing trunk flexion & Tape measure / cm \\
\hline Abdominal muscle strength & Stopwatch/ repetitions during $30 \mathrm{sec}$ \\
\hline 600 -meter run & Stopwatch / sec \\
\hline
\end{tabular}

The Kasch Pulse Recovery Test was used to examine cardiorespiratory fitness. The test consists in stepping up and down a $30.5 \mathrm{~cm}$ step at the rate of 24 steps per minute. Cardiac contraction is monitored throughout the test. Measurement was carried out with an electronic device for heartbeat monitoring. During the test, heartbeat was monitored continuously (i.e. during 3-minute exercise and during 1-minute and 5-second rest in the sitting position). Pulse rate after exercise was included in further analysis. A test was considered incomplete each time its protocol was not followed (e.g. incorrect pace, talking, refusal to do an exercise). A test was stopped when cardiac contraction during exercise exceeded 180 heartbeats per minute for over 15 seconds [10].

Having obtainedthe consent of parents / legal guardians for participation of children in the study, a physiotherapist interviewed the parent / guardians about the perinatal period, development and health of the child, according to the questionnaire. After preliminary qualification, a short warm-up was carried out, followed by the physical and cardiorespiratory fitness test. Children wore sports clothes and shoes. They were given time to rest and to have something to drink between tests, if needed.

The tests for the control group were performed in Primary School No. 45 in Lublin, Poland. The studied group was tested in the Children's University Hospital in Lublin, Poland. The heads of these institutions gave their consent for the tests.

Statistica 13.1 software was used in the statistical analysis. The statistical significance was adopted at $\alpha=0.05$. The normality analysis of distribution of quantitative variables with Shapiro-Wilk test revealed that normal distribution can be observed for the following variables: standing long jump, 50-meter sprint, grip strength, $4 \times 10$-meter shuttle run and 600-meter run. No normality of variable distribution was observed for bar hang, abdominal muscle strength, trunk flexion, pulse rate after exercise and total IPFT score. Pearson's chi^ ${ }^{\wedge}$ test, phi coefficient and Cramer’s V were used to analyse correlations between qualitative variables. In order to identify differences between prematurely 
born children and the control group, Student's t-test was conducted for independent samples in the case of variables with normal distribution, whereas Mann-Whitney U test was performed in the case of variables with no features of normal distribution. The results (shown in Tables) present average values and standard deviation (SD) in the case of variables with normal distribution, whereas median values and the minimum-maximum range are given in the case of variables without normal distribution. Spearman's rank correlation coefficient was used to examine correlations between a child's gestational age week of birth and total IPFT score, results of each IPFT component and pulse rate after exercise.

\section{RESULTS}

With respect to the division into groups, there were 13 (43.3\%) participants with a low physical fitness level and 17 (56.7\%) participants with an average physical fitness level in the group of children born prematurely. On the other hand, in the control group there was one (3.3\%) participant with a low physical fitness level and $29(96.7 \%)$ participants with an average physical fitness level (Fig. 1).

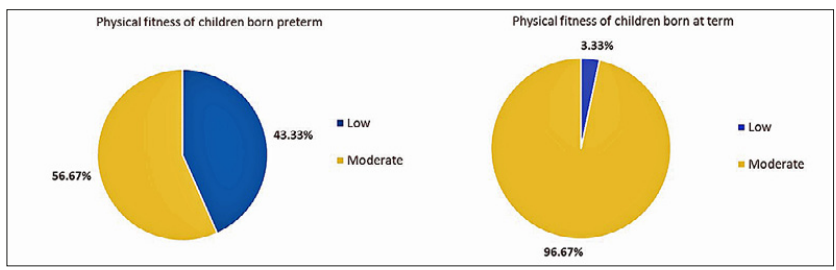

Figure 1. Physical fitness level with respect to the division into the studied group and the control group

A statistically significant correlation was found between physical fitness level in each group $(\mathrm{p}<0.001)$. The group of prematurely born children demonstrated a statistically significant lower physical fitness level than the control group. Phi coefficient value indicates a moderate correlation between these variables (phi=0.47) (Table 4).

Table 4. Results of physical fitness test with respect to the division into the studied group and the control group

\begin{tabular}{|c|c|c|c|c|}
\hline Group & Physical fitness & No. & $\%$ & Pearson's chi^ 2 \\
\hline \multirow[t]{2}{*}{ Studied } & Low & 13 & 43.33 & \multirow{6}{*}{$\begin{array}{c}\quad C h i \wedge 2= \\
13.42 \\
\mathbf{p}=\mathbf{0 . 0 0 0 2 5} \\
\text { phi coefficient } \\
=0.47\end{array}$} \\
\hline & Average & 17 & 56.67 & \\
\hline Total & & 30 & 100 & \\
\hline \multirow[t]{2}{*}{ Control } & Low & 1 & 3.33 & \\
\hline & Average & 29 & 96.67 & \\
\hline Total & & 30 & 100 & \\
\hline
\end{tabular}

Analysis of the results of all IPFT components revealed that statistically significant differences were present in all fitness tests ( $\mathrm{p}<0.05)$, except for standing long jump ( $\mathrm{p}=0.08)$, in which no statistically significant differences between the groups were observed. The prematurely born children achieved considerably lower results in physical fitness tests than children born on time (Tab. 5). Figure 2 presents average scores obtained in the IPFT by the examined children, taking into account the division into the studied group and the control group.
Table 5. Test statistics values. Result of comparison between the groups in terms of IPFT components

\begin{tabular}{lc}
\hline International Physical Fitness Test components & $\mathrm{P}$-value \\
\hline Long jump & $\mathrm{P}<=0.08$ \\
\hline Grip strength & $\mathrm{P}=0.009$ \\
\hline Bar hang & $\mathrm{P}=0.03$ \\
\hline 4x10-meter shuttle run & $\mathrm{P}<0.001$ \\
\hline 50-meter sprint & $\mathrm{P}<0.001$ \\
\hline Abdominal muscle strength & $\mathrm{P}=0.006$ \\
\hline Standing trunk flexion & $\mathrm{P}<0.001$ \\
\hline $600-$ meter run & $\mathrm{P}=0.001$ \\
\hline
\end{tabular}

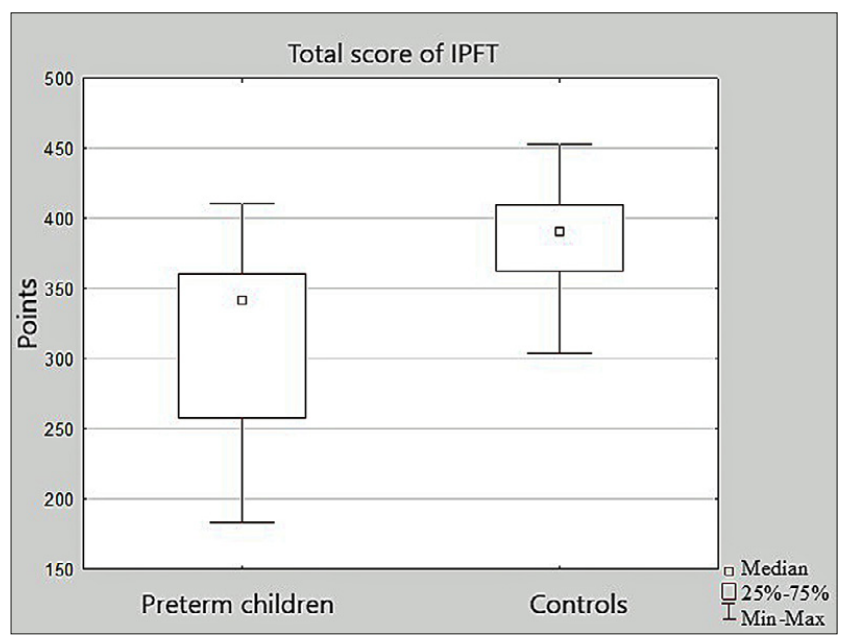

Figure 2. Average total IPFT score for the studied group and the control group

Analysis of particular IPFT components showed that in the studied group the lowest results were achieved in bar hang and the highest in grip strength. In comparison to the control group, the biggest differences were noticeable in trunk flexion, bar hang and 4 x 10-meter shuttle run. On the other hand, the smallest differences were observed in long jump and grip strength tests. Figure 3 presents the range of scores obtained in each test with respect to the division into groups. Average values and standard error are given in the graphs in the case of variables with normal distribution, whereas median values and minimum-maximum values are given in the case of variables without normal distribution (Fig. 3, 4).

Due to the small numbers in particular categories of the 'cardiorespiratory fitness' variable, 3 combined groups were formed: weak cardiorespiratory fitness (very weak + weak), satisfactory cardiorespiratory fitness, good cardiorespiratory fitness (good + very good + perfect) (Fig. 5). There was a statistically significant correlation between a child's time of birth and cardiorespiratory fitness $(p=0.001)$ (Tab. 6). The strength of the correlation between these features was moderate (Cramer's V $=0.47$ ).

Table 6. Comparison between the control group and the studied group in terms of pulse rate after exercise

\begin{tabular}{|c|c|c|c|c|c|c|c|c|}
\hline Variable & Studi & d group & Contr & l group & $\mathrm{U}$ & Z & $p$ & $P$ \\
\hline \multirow{2}{*}{$\begin{array}{l}\text { Pulse } \\
\text { rate after } \\
\text { exercise }\end{array}$} & $\begin{array}{l}\text { Median } \\
\text { value }\end{array}$ & $\begin{array}{l}\text { Minimum- } \\
\text { maximum } \\
\text { range }\end{array}$ & $\begin{array}{l}\text { Median } \\
\text { value }\end{array}$ & $\begin{array}{l}\text { Minimum- } \\
\text { maximum } \\
\text { range }\end{array}$ & \multirow[t]{2}{*}{233.00} & \multirow[t]{2}{*}{3.20} & \multirow{2}{*}{\multicolumn{2}{|c|}{0.001370}} \\
\hline & 123.00 & $\begin{array}{l}97.00- \\
156.00\end{array}$ & 112.00 & $\begin{array}{l}90.00- \\
148.00\end{array}$ & & & & \\
\hline
\end{tabular}




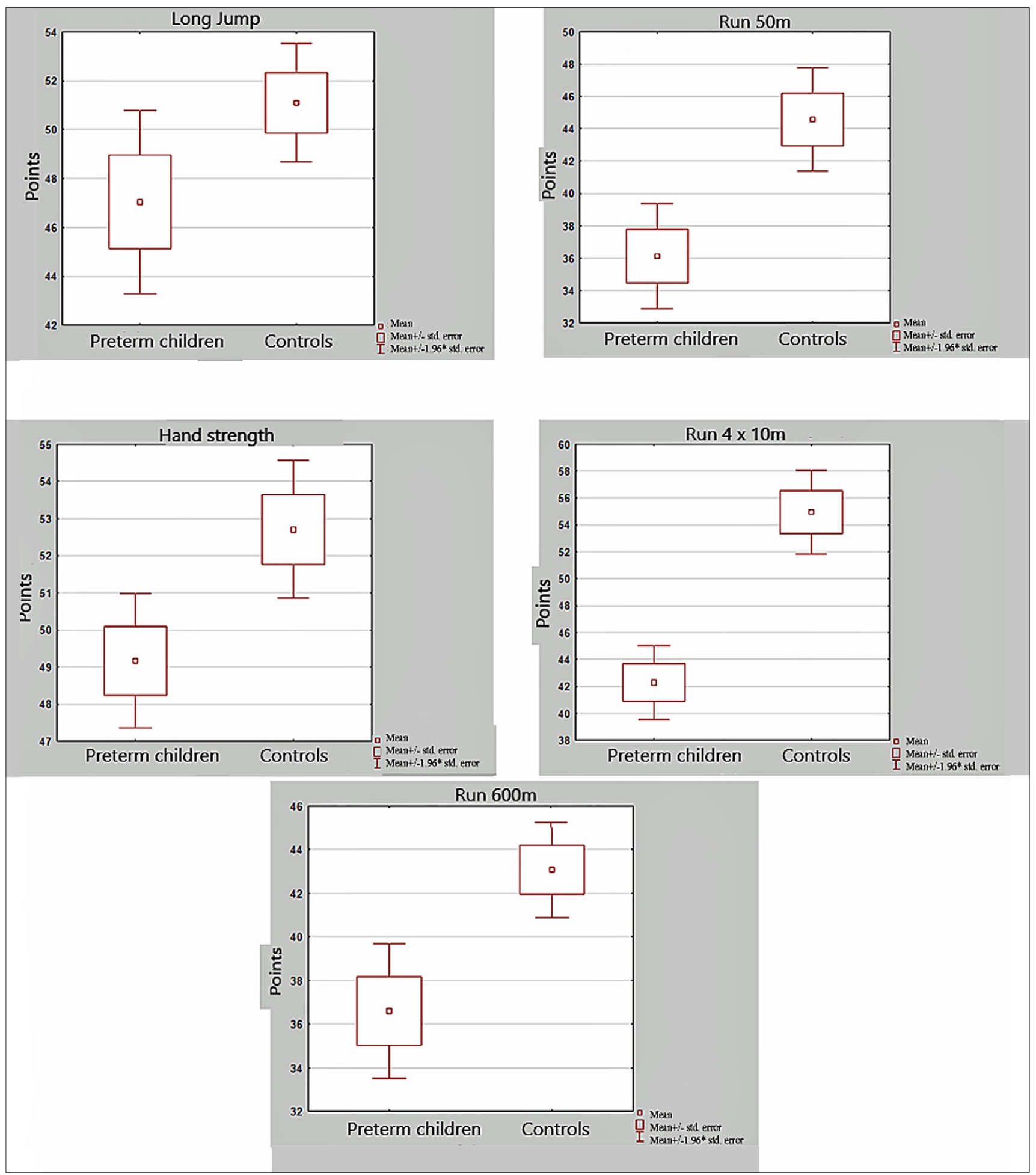

Figure 3. Range of scores achieved in long jump test/ 50-meter sprint test/ grip strength test(hand strengh)/ 4 x10-meter shuttle run test / 600 -meter run test with respect to the division into the studied group and the control group. Box bars presents mean and standard error 

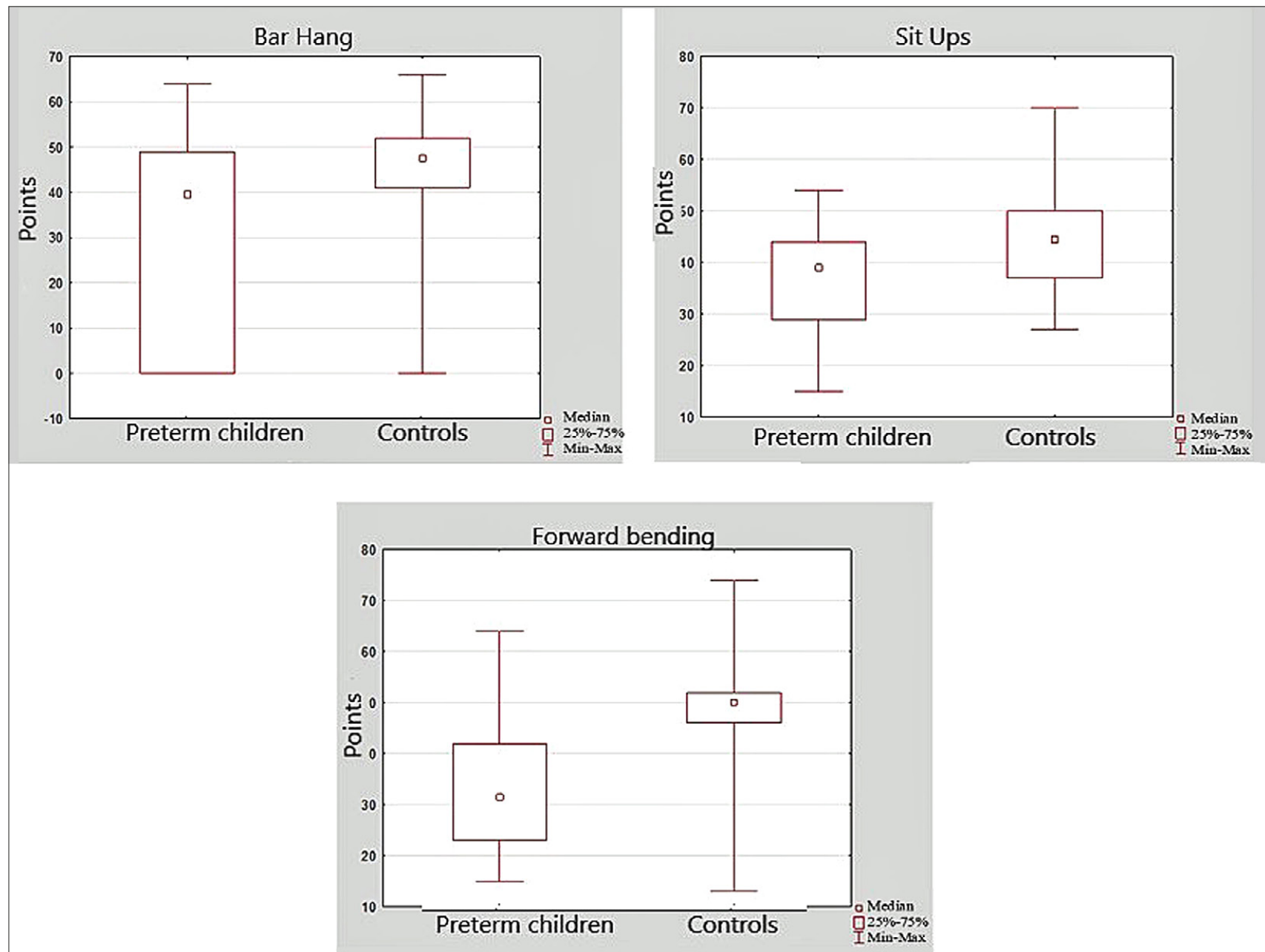

Figure 4. Range of scores obtained in bar hang test / abdominal muscle strength test (sitp-ups) / standing trunk flexion test (forward bending) with respect to the division into the studied group and the control group. Box bars presents median and min.-max. values

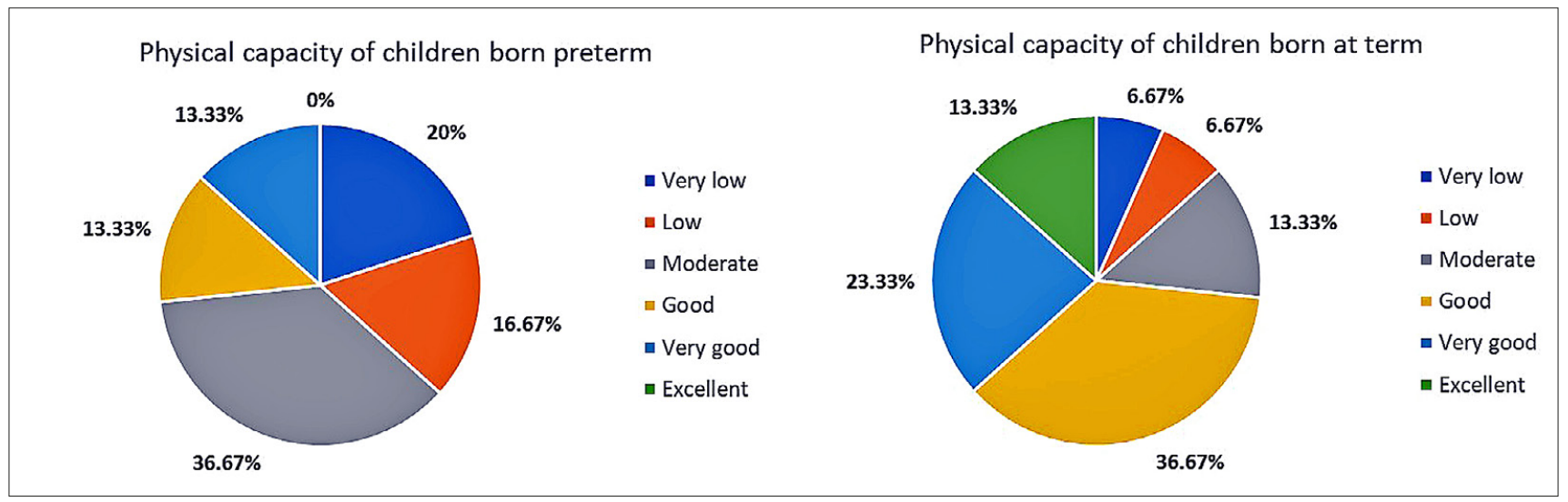

Figure 5. Cardiorespiratory fitness level in the studied and control group

Spearman's rank correlation coefficient was used to examine the correlations between a child's gestational age week of birth and the total result of physical fitness test, result of each component of the test and result of pulse rate measurement. No statistically significant correlation was found between a child's gestational age week of birth, results of physical fitness tests and results of measurement of pulse rate after exercise ( $>>0.05)$ (Fig. 6). 


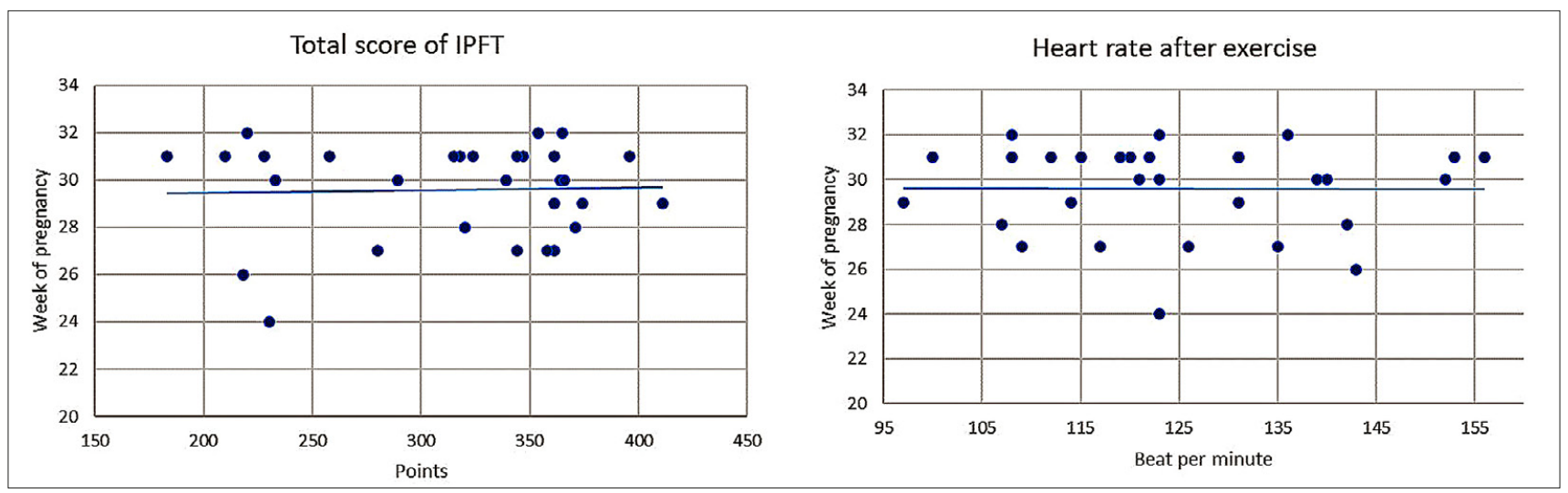

Figure 6. Left: scatter plot presenting correlation between the variables: gestational age week of birth and total IPFT score. Right: scatter plot presenting correlation between the variables: gestational age week of birth and pulse rate after exercise

\section{DISCUSSION}

The physical and cardiorespiratory fitness of those born prematurely has also been evaluated by other authors, most of whom observed that the discussed parameters are lower among prematurely born children and adults. This is noticeable in long-term studies in which it is possible to observe changes occurring over time. Robič Pikel, et al. noted a decrease in body efficiency and fitness in those born prematurely over 10 years. The research covered 396 people: 178 born prematurely and 218 born on time. The evaluation was carried out every year from the age of 8 until 18 [7].

Research conducted in Sweden evaluated the physical abilities of prematurely born men aged between $18-26$. The studied group comprised 218,820 men. The findings indicated that prematurely born healthy men obtained weaker results than men born on time, irrespective of social and economic factors and current body mass index (BMI) [11].

A study comprising 17-year-old teenagers, prematurely born, demonstrated a lower level of respiratory fitness, strength, stamina, flexibility of the locomotor system and activity level. The study used a wide battery of tests and questionnaires to examine body fitness and efficiency. The authors came to the conclusion that differences in fitness and physical activity result from the interaction of the influence of premature birth on the locomotor system coupled with less active lifestyle [12]. Similarly, Tikanmaki et al. found that young adults born prematurely presented lower muscle strength. In their self-assessment, the participants of the research evaluated themselves as less fit than people born on time [5]. In a study of 25-year-old people born prematurely it was demonstrated that their effort tolerance was $10 \%$ lower in comparison to the control group. The authors associated this result with a lower level of physical activity [13]. Adults who were born prematurely are less involved in practising sports and physical activity in their everyday life $[14,15,16]$.

The research conducted by Hamon et al. showed that extremely preterm children displayed considerable airway obstruction caused by physical effort and decreased body efficiency at the age of 7 [6]. Furthermore, in other studies, extremely preterm children had a higher respiratory rate and lower tidal volume during physical effort. However, no differences were observed between the studied group and the control group with respect to physical activity [17]. Research conducted in Canada demonstrated that prematurely born children had lower effort tolerance, altered respiratory mechanics, and increased respiratory response during effort in comparison to children from the control group. The studied group comprised extremely preterm children ( $<28$ week of g.a.) aged $8-12$. The authors found a correlation between lower values of the parameters evaluated and past bronchopulmonary dysplasia [18]. Furthermore, Ruf et al. also proved that past bronchopulmonary dysplasia was connected with decreased effort tolerance in school-age children. The authors associated preterm birth with lower involvement in physical activity and sedentary lifestyle. They suggested that preterm birth, together with lung development complications, had the greatest influence on effort tolerance and physical activity [19].

In the majority of the studies carried out, the authors observed a decreased level of physical and cardiorespiratory fitness in prematurely born people. Many analyses also highlighted a lower amount of physical activity in everyday life and a preference for a sedentary lifestyle among the group of premature children $[12,14,15,16,19]$. Apart from the medical factors predisposing to lower fitness and efficiency of the organism, this may constitute an additional burden and contribute to intensification of the phenomenon. The problem is serious enough to contribute to the incidence of chronic disorders in the future. Cardiological and metabolic diseases, glucose regulation disorders, asthma and increased stroke risk are mentioned most frequently in the context of longterm consequences of preterm birth [2, 20,21]. Considering the number of preterm births on a global scale, the problem may affect a substantial part of society. Due to this fact, medical data concerning childbirth should always be taken into account by experts in all branches of medicine [22].

The authors dealing with long-term evaluation of the discussed aspects suggest the introduction of preventive measures in the form of more physical activity from the earliest years of a child's life [5, 23, 24]. A decreased level of physical and cardiorespiratory fitness may also result in lower motivation for undertaking activities typical of school-age children. Furthermore, limited participation in playing with peers can lead to social exclusion and low self-esteem.

\section{CONCLUSIONS}

In the light of the research carried out, it is concluded that 7-year-old prematurely born children present poorer physical and cardiorespiratory fitness than children born on time. 
Analysis of particular IPFT components demonstrated that the children from the studied group performed relatively well in the grip strength test, in which the smallest differences were also observed in comparison to the control group, as well as in long jump test. On the other hand, bar hang test was the most problematic. The most substantial differences between the groups of examined children were noticeable in bar hang, trunk flexion and $4 \times 10$-meter shuttle run tests. On the basis of the analysis of the development of particular features of human motor activity, it is concluded that prematurely born children obtain poorer results in hand and shoulder strength tests, suppleness and agility, whereas their achievements in hand grip and jumping ability tests are relatively good. The results of cardiorespiratory fitness measurement in the group of prematurely born children are disturbing. The majority of children presented a satisfactory level and none of them obtained a perfect result. In the longterm perspective, permanently low cardiorespiratory fitness may a be a factor predisposing to health problems.

It is necessary to extend the research to include a higher number of patients and carry out long-term observation in order to evaluate the development level of physical and cardiorespiratory fitness of the examined children in their later years of life. Another significant element of further research will be identification of additional factors, i.e. the amount of physical activity in everyday life, BMI, Apgar score, the pace of motor development, the need for rehabilitation in infancy and early childhood, contributing to the development of the evaluated parameters.

The research was approved by the Ethics Committee at the Medical University in Lublin (No. KE-0254/284/2018).

\section{REFERENCES}

1. Machado LCJr, Passini Rjr, Rosa IR, Carvalho HB. Neonatal outcomes of late preterm and early term birth. Eur J Obstet Gynecol Reprod Biol. 2014; 179: 204-208. doi: 10.1016/j.ejogrb.2014.04.042

2. Kajantie E, Strang-Karlsson S, Evensen KAI, Haaramo P. Adult outcomes of being born late preterm or early term - What do we know? Semin Fetal Neonatal Med. 2019; 24(1): 66-83. doi: 10.1016/j. siny.2018.11.001

3. Blencowe H, Cousens S, Oestergaard MZ, Chou D, Moller AB, Narwal $\mathrm{R}$, et al. National, regional, and worldwide estimates of preterm birth rates in the year 2010 with time trends since 1990 for selected countries: a systematic analysis and implications. Lancet. 2012; 9; 379(9832): 2162-72. doi: 10.1016/S0140-6736(12)60820-4

4. Chan E, Leong P, Malouf R, Quigley MA. Long-term cognitive and school outcomes of late-preterm and early-term births: a systematic review. Child Care Health Dev. 2016; 42(3): 297-312. doi: 10.1111/ cch. 12320

5. Tikanmäki M, Tammelin T, Sipola-Leppänen M, Kaseva N, Matinolli HM, Miettola S, et al. Physical Fitness in Young Adults Born Preterm. Pediatrics. 2016; 137(1)e20151289. doi: 10.1542/peds.2015-1289

6. Hamon I, Varechova S, Vieux R, Ioan I, Bonabel C, Schweitzer C, et al. Exercise-induced bronchoconstriction in school-age children born extremely preterm. Pediatr Res. 2013; 73(4 Pt 1): 464-468. doi: $10.1038 /$ pr.2012.202
7. Robič Pikel T, Starc G, Strel J, Kovač M, Babnik J, Golja P. Impact of prematurity on exercise capacity and agility of children and youth aged 8 to 18. Early Hum Dev. 2017; 110: 39-45. doi: 10.1016/j. earlhumdev.2017.04.015

8. Krawczyński M. Wysiłek fizyczny i trening sportowy w wieku rozwojowym. W: Górski J. redaktor Fizjologia wysiłku i treningu fizycznego. PZWL, Warszawa, Polska, 2019: 143-168.

9. Dobosz J. Kondycja fizyczna dzieci i młodzieży w wieku szkolny. Siatki centylowe. AWF, Warszawa, Polska, 2012.

10. Jankowski M, Niedzielska A, Brzezinski M, Drabik J. Cardiorespiratory fitness in children: a simple screening test for population studies. Pediatr Cardiol. 2015; 36(1): 27-32. doi: 10.1007/s00246-014-0960-0

11. Svedenkrans J, Henckel E, Kowalski J, Norman M, Bohlin K. Long-term impact of preterm birth on exercise capacity in healthy young men: a national population-based cohort study. PLoS One. 2013, 6; 8(12) e80869. doi: 10.1371/journal.pone.0080869

12. Rogers M, Fay TB, Whitfield MF, Tomlinson J, Grunau RE. Aerobic capacity, strength, flexibility, and activity level in unimpaired extremely low birth weight $(\leq 800 \mathrm{~g})$ survivors at 17 years of age compared with term-born control subjects. Pediatrics. 2005; 116(1): 58-65. doi: 10.1542/ peds.2004-1603

13. Clemm HH, Vollsæter M, Røksund OD, Eide GE, Markestad T, Halvorsen T. Exercise capacity after extremely preterm birth. Development from adolescence to adulthood. Ann Am Thorac Soc. 2014; 11(4): 537-45. doi: 10.1513/AnnalsATS.201309-311OC

14. Tikanmäki M, Kaseva N, Tammelin T, Sipola-Leppänen M, Matinolli HM, Eriksson JG, et al. Leisure Time Physical Activity in Young Adults Born Preterm. J Pediatr. 2017; 189: 135-142. doi: 10.1016/j. jpeds.2017.06.068

15. Kajantie E, Strang-Karlsson S, Hovi P, Räikkönen K, Pesonen AK, Heinonen $\mathrm{K}$, et al. Adults born at very low birth weight exercise less than their peers born at term. J Pediatr. 2010; 157: 610-616. doi: 10.1016/j. jpeds.2010.04.002

16. Kaseva N, Wehkalampi K, Strang-Karlsson S, Salonen M, Pesonen AK, Räikkönen K, et al. Lower conditioning leisure-time physical activity in young adults born preterm at very low birth weight. PloS One. 2012; 7(2)e32430. doi: 10.1371/journal.pone.0032430

17. Welsh L, Kirkby J, Lum S, Odendaal D, Marlow N, Derrick G, et al. The EPICure study: maximal exercise and physical activity in school children born extremely preterm. Thorax. 2010; 65: 165-72. doi: 10.1136/ thx.2008.107474

18. MacLean JE, DeHaan K, Fuhr D, Hariharan S, Kamstra B, Hendson $\mathrm{L}$, et al. Altered breathing mechanics and ventilatory response during exercise in children born extremely preterm. Thorax. 2016; 71(11): 1012-1019. doi: 10.1136/thoraxjnl-2015-207736

19. Ruf K, Thomas W, Brunner M, Speer CP, Hebestreit H. Diverging effects of premature birth and bronchopulmonary dysplasia on exercise capacity and physical activity - a case control study. Respir Res. 2019; 21; 20(1): 260. doi: 10.1186/s12931-019-1238-0

20. Kajantie E, Hovi P. Is very preterm birth a risk factor for adult cardiometabolic disease? Semin Fetal Neonatal Med. 2014; 19(2): 112-7. doi: 10.1016/j.siny.2013.11.006

21. Pilgaard K, Færch K, Carstensen B, Poulsen P, Pisinger C, Pedersen O, et al. Low birthweight and premature birth are both associated with type 2 diabetes in a random sample of middle-aged Danes. Diabetologia. 2010; 53(12): 2526-30. doi: 10.1007/s00125-010-1917-3

22. Raju TNK, Buist AS, Blaisdell CJ, Moxey-Mims M, Saigal S. Adults born preterm: a review of general health and system-specific outcomes. Acta Paediatr. 2017; 106(9): 1409-1437. doi: 10.1111/apa.13880

23. Malleske DT, Chorna O, Maitre NL. Pulmonary sequelae and functional limitations in children and adults with bronchopulmonary dysplasia. Paediatr Respir Rev. 2018; 26: 55-59. doi: 10.1016/j.prrv.2017.07.002

24. Smith, JJ, Eather N, Morgan PJ, Plotnikoff RC, Faigenbaum AD, Lubans DR. The health benefits of muscular fitness for children and adolescents: a systematic review and meta-analysis. Sports Med. 2014; 44(9): 120923. doi: 10.1007/s40279-014-0196-4 